\title{
Fabrication and Evaluation of Polycaprolactone/Gelatin-Based Electrospun Nanofibers with Antibacterial Properties
}

\author{
Lor Huai Chong, ${ }^{1}$ Mim Mim Lim, ${ }^{1}$ and Naznin Sultana ${ }^{1,2}$ \\ ${ }^{1}$ Faculty of Biosciences and Medical Engineering, Universiti Teknologi Malaysia, 81310 Johor, Malaysia \\ ${ }^{2}$ Advanced Membrane Technology Research Centre, Universiti Teknologi Malaysia, 81310 Johor, Malaysia \\ Correspondence should be addressed to Naznin Sultana; naznin@biomedical.utm.my
}

Received 8 September 2014; Accepted 27 November 2014

Academic Editor: Qi Wang

Copyright (c) 2015 Lor Huai Chong et al. This is an open access article distributed under the Creative Commons Attribution License, which permits unrestricted use, distribution, and reproduction in any medium, provided the original work is properly cited.

\begin{abstract}
Nanofibrous scaffolds were fabricated through blending of a synthetic polymer, polycaprolactone (PCL), and a natural polymer, gelatin (GE), using an electrospinning technique. Processing and solution parameters were optimized to determine the suitable properties of PCL/GE-based nanofibers. Several characterizations were conducted to determine surface morphology by scanning electron microscopy (SEM), wettability using water contact angle measurement, and chemical bonding analysis using attenuated total reflectance (ATR) of PCL/GE-based nanofibers. Experimental results showed that $14 \%(\mathrm{w} / \mathrm{v}) \mathrm{PCL} / \mathrm{GE}$ with a flow rate of $0.5 \mathrm{~mL} / \mathrm{h}$ and $18 \mathrm{kV}$ demonstrated suitable properties. This nanofiber was then further investigated for its in vitro degradation, drug loading (using a model drug, tetracycline hydrochloride), and antibacterial testing (using zone inhibition method).
\end{abstract}

\section{Introduction}

In cases of full-thickness burns or deep ulcers, there are no remaining sources of cells for tissue regeneration and recovery [1]. These severely injured parts will deteriorate further if a patient has diabetes [2]. Hence, tissue engineering (TE) technology is crucial to solve this issue. TE provides an alternative pathway for tissue regeneration and recovery using polymeric biomaterials [3] to harvest tissues for transplantation [4] from the patient's own cells. In human skin, extracellular matrix (ECM) is a key element in monitoring cell behavior while scaffold design is the most important component in TE [5]. Biomaterials scaffolds play a pivotal role in providing a synthetic but suitable ECM environment for growing cells and drug delivery in severely injured skin [6].

Recently, the rapid growth of nanotechnology has spurred the development of nanofibrous scaffolds [7]. There are many fabrication techniques including phase separation, selfassembly, and electrospinning [8]. Among these, electrospinning is the most widely used [9]. The technique of electrospinning is dependent on several types of parameters, including solution parameters such as concentration, viscosity, and solution conductivity and processing parameters such as voltage applied, temperature, flow rate, and distance between tip of syringe and collector [10-12]. Electrospinning technology has led to wide interest in scaffold fabrication, in the main because the biological and mechanical properties of nanofibers can be easily manipulated by altering the solution and processing parameters [13]. Electrospinning is a relatively simple technique for fabricating highly porous nanosize scaffolds from a wide variety of polymers including biopolymers such as gelatin, collagen, and fibrinogen [14] on a large scale. The large surface area to volume ratio of nanofibers enhances the diffusion efficiency of nutrient and gaseous exchange [15]. Porosity, air permeability, and surface wettability of nanofibers are important elements for regenerating skin tissue [16]. Also electrospinning is able to fabricate nanofibers with similar morphology and architectural features to the natural ECM in skin [13]. In addition, biodegradable scaffolds are able to degrade and thus change their structure over time to seeded cells in order to proliferate and produce their own ECM [17]. Using biodegradable polymer via electrospinning is important in skin to avoid the need for surgical removal [18].

Recent studies have shown that PCL/GE can be used for dermal reconstitution [13] and wound healing or wound dressing [19]. However, there is less research on the antibacterial testing of PCL/GE nanofibers for the application 
of skin tissue regeneration. It is essential to apply antibiotic to the severely injured part of the skin via a drug delivery system to reduce inflammation caused by bacterial infection [20]. Therefore, it is important to fabricate an antibacterial test for PCL/GE-based nanofibers to avoid the interference of bacteria with cell activities during tissue regeneration and repair. Kenawy et al.s research demonstrated the potential of electrospun nanofibers as effective carriers for drug delivery and tetracycline hydrochloride was used in the research [21]. According to Bhardwaj and Kundu's research, tetracycline has been found to prevent skin inflammation from bacterial infection [14]. However, there is still no report investigating the antibacterial activities of tetracycline hydrochloride in PCL/GE nanofibers for skin loss application.

In this paper, PCL/GE-based nanofibers were fabricated using the electrospinning technique by varying certain parameters. Characterizations and degradation tests were carried out to determine potential nanofibers for further investigation. Tetracycline hydrochloride was loaded into PCL/GE-based nanofibers and tested on their antibacterial activity against Gram-negative and Gram-positive bacteria.

\section{Materials and Methods}

2.1. Materials. Polymer of GE powder from porcine skin, PCL pellets $(\mathrm{Mw}=70,000-90,000)$, and solvent of formic acid (density: $1.22 \mathrm{~g} / \mathrm{mL}$ ) were purchased from SigmaAldrich. The drug (antibiotic) used in this study was tetracycline hydrochloride, obtained from Calbiochem.

\subsection{Methods}

2.2.1. Preparation of PCL/GE-Based Polymer Solutions. Three different polymer blend solutions of PCL/GE, which were $12 \%(\mathrm{w} / \mathrm{v})(\mathrm{PCL}=1.0 \mathrm{~g} ; \mathrm{GE}=0.2 \mathrm{~g}), 14 \%(\mathrm{w} / \mathrm{v})(\mathrm{PCL}=1.0 \mathrm{~g}$; $\mathrm{GE}=0.4 \mathrm{~g})$, and $18 \% \mathrm{w} / \mathrm{v}(\mathrm{PCL}=1.0 \mathrm{~g} ; \mathrm{GE}=0.8 \mathrm{~g})$, were prepared by dissolving different amounts of PCL pellets and GE powder into $10 \mathrm{~mL}$ formic acid. Based on the solution properties, $14 \% \mathrm{w} / \mathrm{v}$ was found to be suitable for producing nanofibers. The PCL pellets and GE power were dissolved completely in formic acid by stirring magnetically using a magnetic stirrer (LABMART HTS-1003) at $600 \mathrm{rpm}$ at room temperature for up to three hours.

2.2.2. Fabrication of PCL/GE-Based Electrospun Nanofibers. An electrospinning unit (NaBond, China) was used in the fabrication of PCL/GE-based nanofibers. The prepared polymer solution (12\% [w/v] PCL/GE-based) was transferred into a $5 \mathrm{~mL}$ syringe with the constant flow rate of $0.5 \mathrm{~mL} / \mathrm{h}$ using an infusion pump (Veryark TCV-IV, China). Once high voltage at $18 \mathrm{kV}$ was applied to the needles of the syringe, a fluid jet was ejected from the needles and accelerated towards a grounded collector $(10 \mathrm{~cm} \times 10 \mathrm{~cm})$ aluminum sheet. The needle was placed at a distance of $10 \mathrm{~cm}$ away from the aluminum collector. The polymer solution was evaporated and the charged polymer fibers were deposited on the collector in the form of nanofibers. These steps were repeated with $14 \%(\mathrm{w} / \mathrm{v})$ and $18 \%(\mathrm{w} / \mathrm{v})$ PCL/GE-based polymer solution.

\subsubsection{Characterization of PCL/GE-Based Electrospun Nanofibers}

Morphology. First, the electrospun nanofibers were coated with gold. Then, the surface morphology of the coated PCL/GE-based electrospun nanofibers was obtained by SEM (Hitachi TM 3000, Japan) at an accelerating voltage of $15 \mathrm{kV}$ and a field emission scanning electron microscope (FESEM). The obtained images were further analyzed to examine fiber diameters and pore size diameters by J-Image. At least 30 fibers were measured for their fiber diameters and pore sizes and the average and standard deviations were plotted.

Attenuated Total Reflectance (ATR): Fourier Transform Infrared Spectroscopy (FTIR). Chemical bonding of PCL and PCL/GE was determined by ATR-FTIR (Perkin-Elmer 5 Series, USA) over a range of 400 to $4000 \mathrm{~cm}^{-1}$.

Contact Angle. Wettability of hydrophilicities of PCL/GEbased electrospun nanofibers was examined through a contact angle measuring system (VCA Optima, AST Products, Inc.) and further analyzed using VCA Optima software. The size of dropping deionized water was $3 \mu \mathrm{L}$.

2.2.4. In Vitro Degradation Study. The selected sample of nanofibers was cut into $1 \mathrm{~cm}^{2}$ pieces and immersed in phosphate buffered saline (PBS, $\mathrm{pH}=7.4$ ) and incubated in vitro at $37^{\circ} \mathrm{C}$ for different periods of time (day 1 and day 14). After each degradation period, the nanofibers were washed and subsequently dried in room temperature for 24 hours. The morphologies of degraded nanofibers were observed with field emission scanning electron microscopy (FESEM) and the fiber diameters were calculated using J-Image.

2.2.5. Drug Loading. Tetracycline hydrochloride was used as the model drug (antibiotics) in this study. It had to be predissolved in methanol before being added to the spinning solution. Tetracycline $0.2 \mathrm{~g}$ was prepared to be predissolved in $10 \mathrm{~mL}$ methanol to load $2 \%(\mathrm{w} / \mathrm{v})$ of tetracycline hydrochloride into the nanofibers. After all the tetracycline hydrochloride was completely predissolved into methanol, just $1 \mathrm{~mL}$ of tetracycline hydrochloride solution was taken out and added to the blended polymer solution selected. After mixing the $1 \mathrm{~mL}$ of $2 \% \mathrm{w} / \mathrm{v}$ tetracycline hydrochloride with the blended polymer solution, electrospinning was then carried out to fabricate PCL/GE-based nanofibers with tetracycline hydrochloride.

2.2.6. Antibacterial Tests. Antibacterial activity of tetracycline hydrochloride-loaded PCL/GE-based electrospun nanofibers was investigated by zone inhibition method. Tetracycline hydrochloride-incorporated PCL/GE nanofibers were cut into $14 \mathrm{~mm}$ diameter circular discs. Escherichia coli (Gram-negative bacteria) and Bacillus cereus (Gram-positive bacteria) were chosen as model microorganisms in this study. 

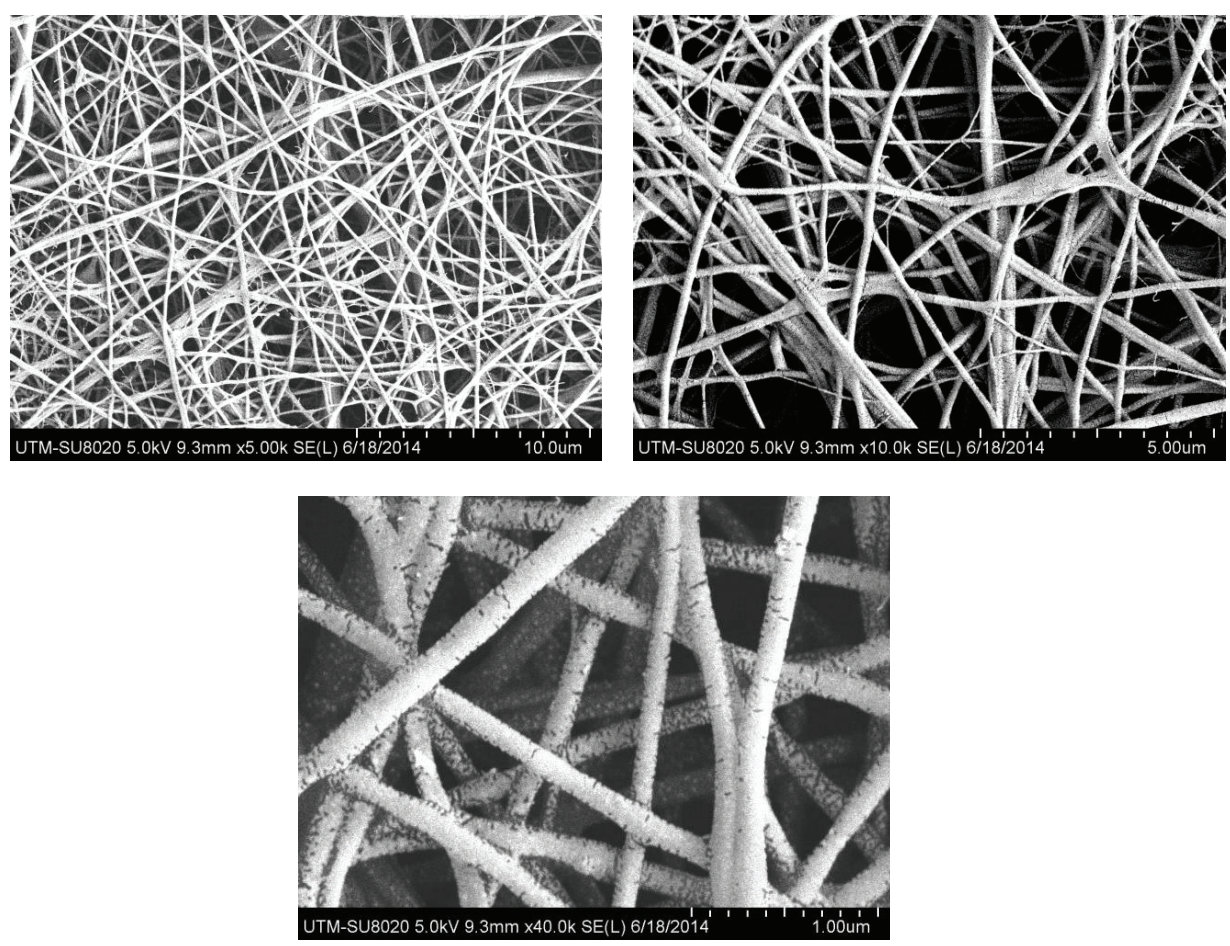

FIGURE 1: FESEM micrographs of $14 \%$ w/v PCL/GE-based nanofibers at different magnification.

The spread plate method was used as nutrient agar plates were inoculated with $1 \mathrm{~mL}$ of bacterial suspension which contained around $10^{8} \mathrm{cfu} / \mathrm{mL}$ for each type of bacteria. Nanofibers were gradually placed on the inoculated plates and incubated for 24 hours at $37^{\circ} \mathrm{C}$. Zones of inhibition were determined by calculating the diameter of clear area formed around each of the nanofibers.

2.2.7. Statistical Analysis. Three to five samples were tested and the average and standard deviations were plotted and analyzed.

\section{Results and Discussion}

3.1. Morphology of PCL/GE-Based Nanofibers. Figure 1 shows the microstructures of PCL/GE-based nanofibers fabricated from $14 \% \mathrm{w} / \mathrm{v}$ PCL/GE-based solution. Electrospun PCL/GEbased nanofibers produced from lower concentrations had unwanted beads because of low polymer concentration. The fibers were in wet form when reaching the collector during the electrospinning process. Thus unwanted bead formation occurred. Fewer beads were observed with the increase of solution concentration. However, if the blended polymer solution was too concentrated, it was difficult to eject the fluid jet from the needles and to accelerate it toward a grounded collector. In some cases, the droplet of overconcentrated polymer solution might dry out at the tip and halt the electrospinning process.

The diameter and pore sizes of electrospun nanofibers are presented in Figure 2. According to Figure 2(a), the average fiber diameter increased with the increasing concentration of the polymer solution. Concentrations of $12 \%, 14 \%$, and $18 \% \mathrm{w} / \mathrm{v}$ PCL/GE-based nanofibers attained fiber diameters of $15.9 \mathrm{~nm}, 87.7 \mathrm{~nm}$, and $547.6 \mathrm{~nm}$, respectively. Higher viscosity resistance as a result of higher concentration of the blended solution fails to maintain its flow at the tip of needles. Hence, a large size of nanofibers formation is obtained. Basically, a small fiber diameter is much preferred over a larger size due to its high surface area to volume ratio which is able to enhance its nutrient and gaseous delivery efficiency as well as drug loading and drug release via the diffusion process. On the other hand, the pore size of the nanofibers was also examined for the polymer concentration of $12 \% \mathrm{w} / \mathrm{v}, 14 \% \mathrm{w} / \mathrm{v}$, and $18 \% \mathrm{w} / \mathrm{v}$ (Figure $2(\mathrm{~b})$ ). It was found that $14 \% \mathrm{w} / \mathrm{v}$ had the highest pore size, which was around $178.42 \mathrm{~nm}$. Larger pore size improves cell activities such as cell migration and cell proliferation. From the surface morphology characterization, the average fiber diameters and pore size of $14 \% \mathrm{w} / \mathrm{v}$ displayed the optimum characteristic which is needed for skin tissue regeneration.

3.2. ATR-FTIR. ATR-FTIR analysis was done to identify the intermolecular interaction between PCL- and PCL/GEbased electrospun nanofibers. According to the spectrum shown in Figure 3, PCL and PCL/GE have the same infrared spectra showing that they have similar chemical bonding. The common band included $2,949 \mathrm{~cm}^{-1}$ (asymmetric $\mathrm{CH}_{2}$ stretching), $2,865 \mathrm{~cm}^{-1}$ (symmetric $\mathrm{CH}_{2}$ stretching), $1,727 \mathrm{~cm}^{-1}$ (carbonyl stretching), $1,293 \mathrm{~cm}^{-1}$ (C-O and C-C stretching), and $1,240 \mathrm{~cm}^{-1}$ (asymmetric COC stretching).

The only difference in bands between PCL and PCL/GE was the presence of an amide group $\left(\mathrm{NH}_{2}\right)$ in PCL/GE. 


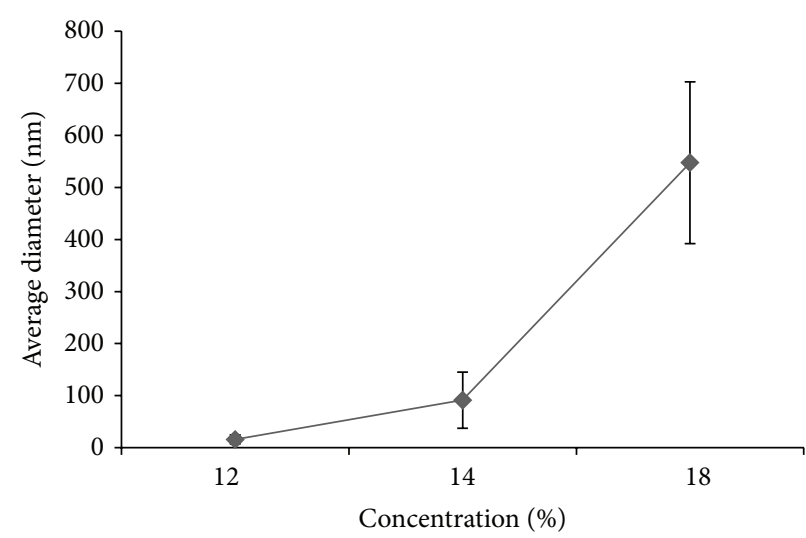

(a)

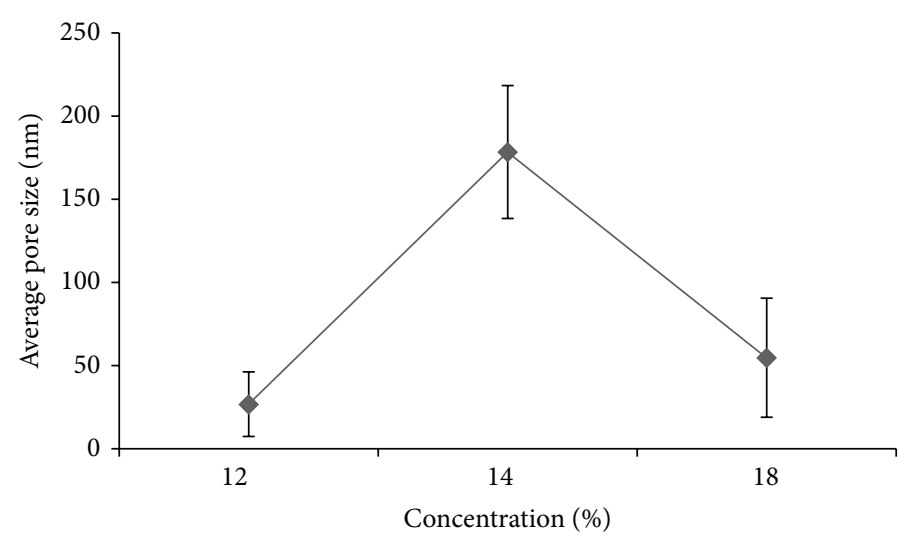

(b)

FIGURE 2: Average fiber diameters (a) and average pores sizes (b) of PCL/GE-based electrospun nanofibers fabricated from $12 \%$ w/v, $14 \%$ w/v, and $18 \% \mathrm{w} / \mathrm{v} \mathrm{PCL} / \mathrm{GE}-$ based polymer solution.

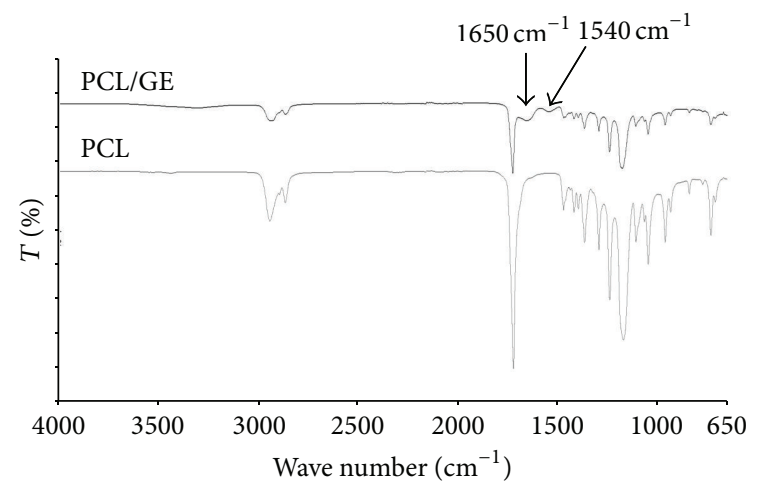

FIGURE 3: ATR- FTIR spectra of PCL- and PCL/GE-based nanofibers.

The bands of GE appeared at approximately $1,650 \mathrm{~cm}^{-1}$ (amide I) and 1,540 $\mathrm{cm}^{-1}$ (amide II). The presence of an amide group confirms the presence of GE in nanofibers after polymer blending and electrospinning. Amide groups in gelatin are able to form hydrogen bonds with water molecules. Thus gelatin has the ability to increase the hydrophilicity of PCLbased nanofibers.

3.3. Water Contact Angle. Since the PCL/GE-based nanofibers that we fabricated are intended to be used in skin tissue regeneration, contact with water, blood, and other bodily fluids is frequent. Thus it is essential to characterize the PCL/GE-based nanofibers for their wettability. The wettability of the fiber was measured using water contact angle. Table 1 demonstrates the contact angle of water on the surface of nanofibers produced at different concentrations.

It was observed that the nanofibers of $12 \%(\mathrm{w} / \mathrm{v})$ showed the highest contact angle of $98^{\circ} \pm 2.0^{\circ}$ compared to those of $14 \%(\mathrm{w} / \mathrm{v})$ which were $49.5^{\circ} \pm 3.2^{\circ}$. When the amount of GE increased to $0.8 \mathrm{~g}$, the contact angle decreased significantly and it was absorbed completely on the surface as GE is highly hydrophilic in nature. The contact angle of nanofibers showed
TABLE 1: Contact angle of PCL/GE-based electrospun nanofibers produced from different polymer concentrations.

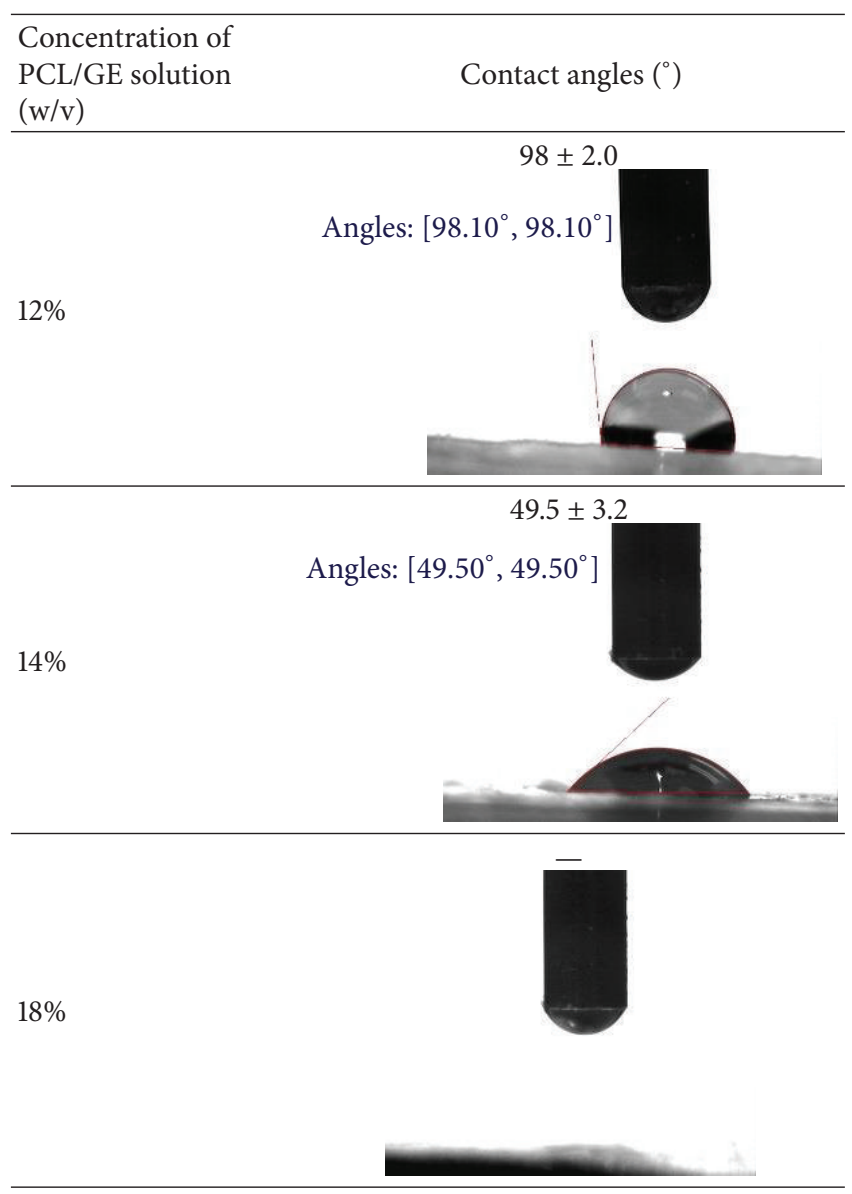

hydrophilic property with less than $90^{\circ}$ value. Since $14 \% \mathrm{w} / \mathrm{v}$ PCL/GE-based nanofibers exhibit the most optimum characteristics such as smaller fiber diameters, largest pore size, and good hydrophilicity, they were thus chosen for further analysis and characterization. 


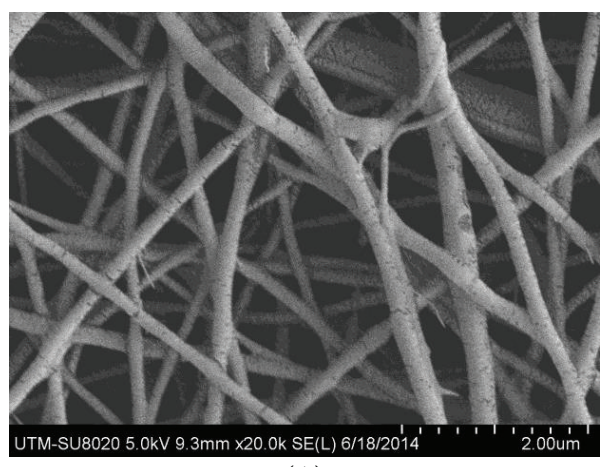

(A)

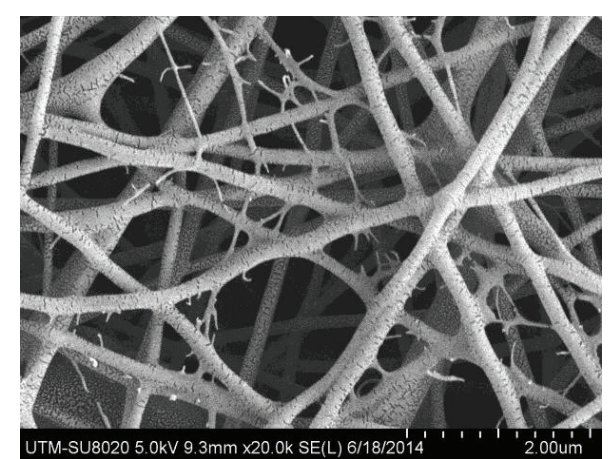

(B)

(a)

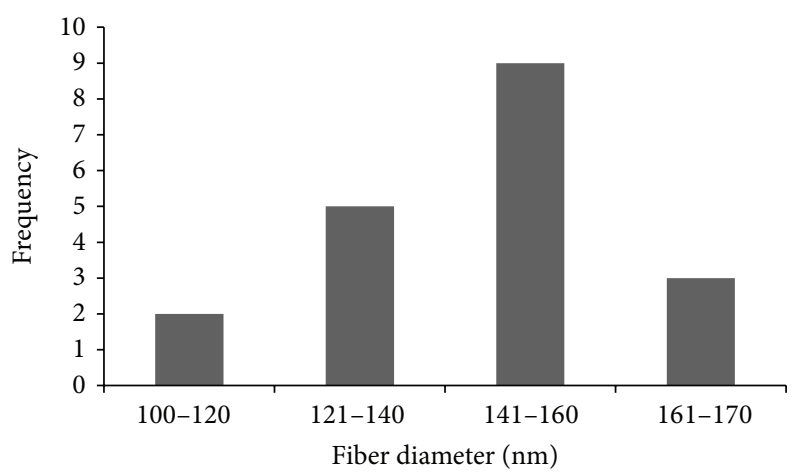

(b)

FIGURE 4: FESEM micrographs of (a) 14\% w/v PCL/GE-based nanofibers: as-fabricated (A) and degraded (B); (b) distribution of fiber diameters in $14 \% \mathrm{w} / \mathrm{v}$ PCL/GE-based nanofibers after degradation.

The GE component in PCL/GE nanofibers is expected to be gradually dissolved when it comes into contact with water (or bodily fluid); hence, it is able to create more space for cell growth and cell migration. Similarly, the good deformation properties of GE provide easier opening of space to harvest the skin tissue and cells. It is not easy to fabricate desired pore sizes through electrospinning due to the random deposited fibers. However, the overall network architecture structure fabricated is similar and able to mimic the natural ECM, providing the advantage in the process of skin tissue regeneration and repair.

3.4. In Vitro Degradation. The ability of nanofibers to degrade was evaluated through soaking them in PBS solution for 14 days using a sample of $14 \%(\mathrm{w} / \mathrm{v})$. The morphology of asfabricated and degraded PCL/GE nanofibers was studied by FESEM. The FESEM images are shown in Figure 4(a). At day 14 , it was observed that many fibers were broken down. The diameter range of degraded nanofibers was in the range of $26.7 \mathrm{~nm}-206 \mathrm{~nm}$, with average diameters of $127.29 \mathrm{~nm}$. Figure 4(b) shows the distribution of nanofiber diameters. The broken fibers and the percentages of weight loss (Table 2 and Figure 5) from 3.3\% (day 7) to $15.5 \%$ (day 14) indicated that the blended nanofibers were successfully degraded due to the presence of GE, which has a faster degradation rate than PCL ( $0 \%$ for both day 7 and day 14$)$. Consisting of an amide group, GE was able to form a hydrogen bond with water
TABLE 2: The percentages of weight loss for 14\% PCL-based nanofibers and $14 \%$ PCL/GE-based nanofibers.

\begin{tabular}{lcc}
\hline Days & PCL $(\%)$ & PCL/GE (\%) \\
\hline 0 & 0.0 & 0.0 \\
7 & 0.0 & $3.3 \pm 1.1$ \\
14 & 0.0 & $15.5 \pm 2.0$ \\
\hline
\end{tabular}

molecule. These biodegradable and hydrophilic properties of $14 \% \mathrm{w} / \mathrm{v}$ PCL/GE-based nanofibers are beneficial to skin tissue regeneration.

3.5. Drug Loading. It is important to load antibiotics into PCL/GE-based nanofibers to reduce inflammation caused by bacterial infection during the process of recovery activities, since the injured part of skin is an ideal environment for microbial growth. The 14\% PCL/GE-based nanofibers incorporated with tetracycline hydrochloride were examined using EDX and FESEM (Figure 6(a)). Meanwhile, smooth fibers with no bead formation and decrement in average fiber diameter were observed in the FESEM image, as shown in Figure 6(b).

3.6. Antibacterial Tests. It is essential to carry out antibacterial tests on tetracycline hydrochloride-loaded PCL/GEbased nanofibers to investigate the potential of nanofibers 


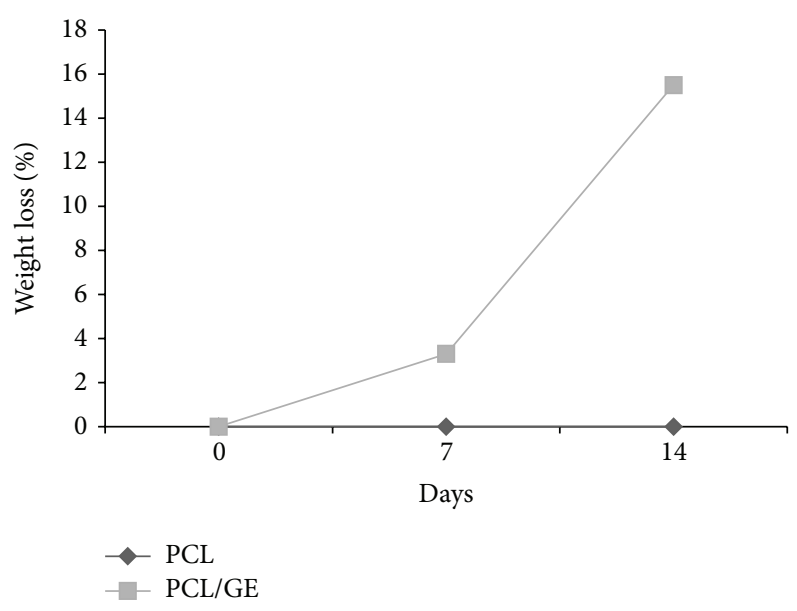

Figure 5: The percentages of weight loss of PCL- and PCL/GE-based nanofibers in day 7 and day 14.

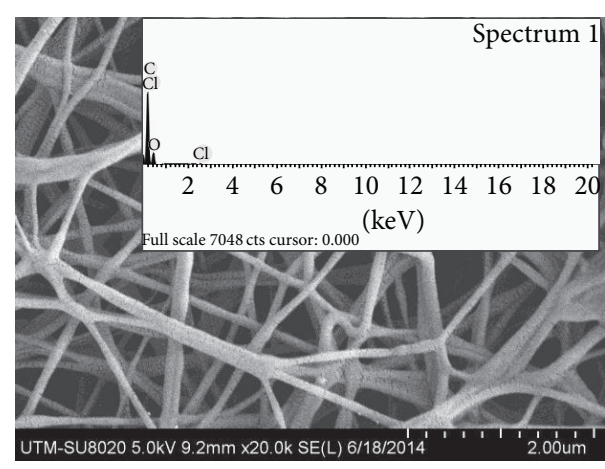

(a)

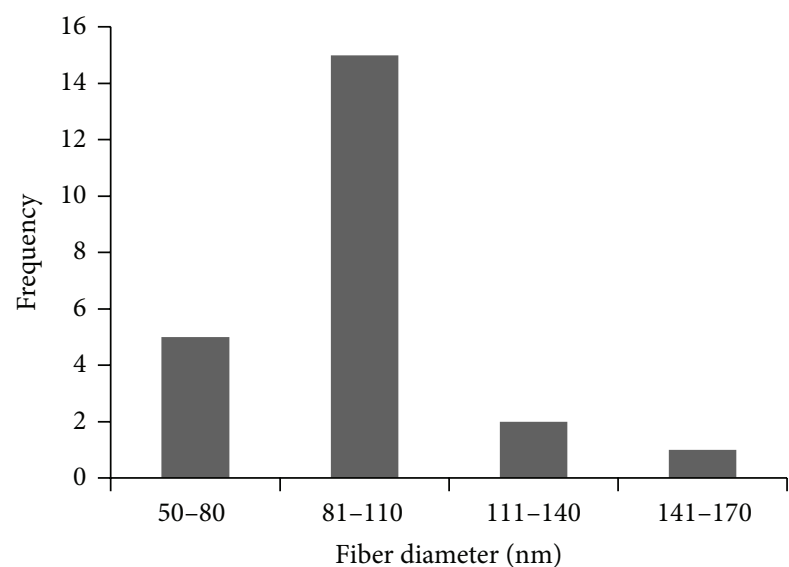

(b)

FIGURE 6: FESEM micrograph and EDX spectrums of 14\% w/v PCL/GE-based electrospun nanofibers with tetracycline hydrochloride (a) and its fiber diameter distribution (b).

in the inhibition of bacterial growth. The antibacterial tests were performed using the zone inhibition method by examining the antibacterial activities against two types of bacteria, Bacillus cereus (Gram-positive bacteria) and Escherichia coli (Gram-negative bacteria). Figure 7 displays the inhibition zone of the nanofibers while Table 3 shows the diameters of the inhibition zone. Based on the result observed, the drug-loaded nanofibers showed a large area of zone inhibition toward the two bacteria. The initial diameter of nanofibers was $14 \mathrm{~mm}$. The diameters of clear inhibition were at least double the initial diameter. This result indicates that tetracycline hydrochloride possesses efficient antibacterial property and a small amount of tetracycline hydrochloride $(2 \%)$ is enough to inhibit a large area of bacterial growth. The drug-loaded nanofibers fabricated should be able to prevent the growth of bacteria responsible for severe harm to skin tissue, thus aiding the tissue regeneration process and effectively avoiding exogenous infections.
TABLE 3: Antibacterial activity of tetracycline hydrochloride-loaded PCL/GE-based nanofibers (14\%w/v) against Bacillus cereus and Escherichia coli.

\begin{tabular}{lc}
\hline Bacteria & The diameter of inhibition zone $(\mathrm{mm})$ \\
\hline Bacillus cereus & $34 \pm 0.5$ \\
Escherichia coli & $30 \pm 1.2$ \\
\hline
\end{tabular}

\section{Conclusions}

PCL/GE-based electrospun nanofibers were successfully fabricated using the electrospinning technique. Suitable fibers with suitable properties were fabricated with $14 \% \mathrm{w} / \mathrm{v}$ of $\mathrm{PCL} / \mathrm{GE}$ with flow rate $0.5 \mathrm{~mL} / \mathrm{h}$ and $18 \mathrm{kV}$. Results from these experiments confirmed that $14 \% \mathrm{w} / \mathrm{v}$ PCL/GE was in the range of ideal porosity and was able to degrade with time. It was possible to incorporate drugs into the nanofibers. The $14 \%$ PCL/GE-based nanofibers with tetracycline hydrochloride showed clear inhibition zones against Gram-positive and 


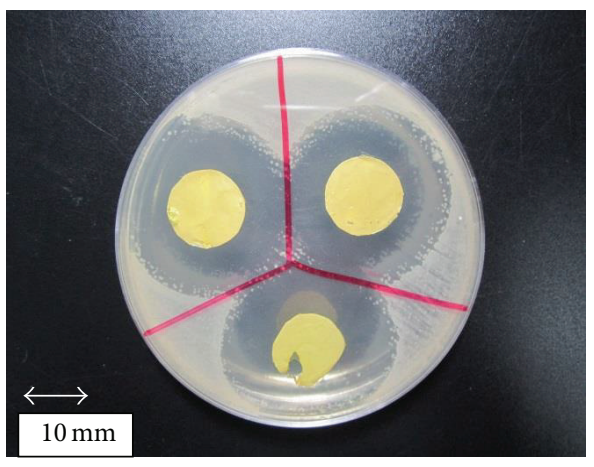

(a)

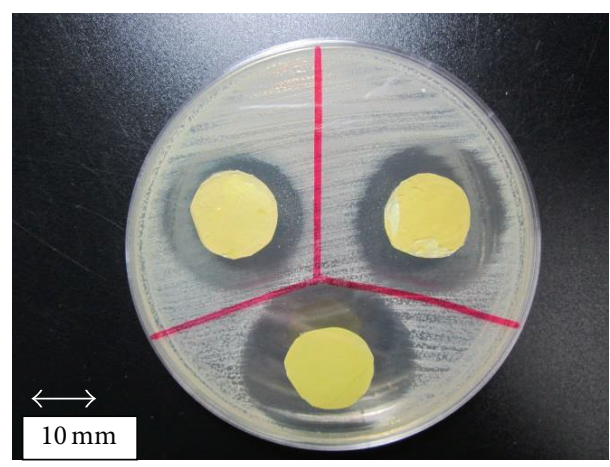

(b)

FIgURE 7: Antibacterial activity of 14\% w/v PCL/GE-based nanofiber: (a) Bacillus cereus and (b) Escherichia coli.

Gram-negative bacteria. The nanofibers are suitable for use in inhibiting bacterial infections and protect the injured part of both skin and tissues from contamination during skin tissue engineering.

\section{Conflict of Interests}

The authors do not have any conflict of interests.

\section{Acknowledgments}

The authors acknowledge MOHE, GUP Tier 1 Grants (Vot: 05H07, 06H84), FRGS (Vot: 4F507), MOHE, UTM, and RMC for financial support. Lab facilities of FBME are also acknowledged.

\section{References}

[1] J. J. Marler, J. Upton, R. Langer, and J. P. Vacanti, “Transplantation of cells in matrices for tissue regeneration," Advanced Drug Delivery Reviews, vol. 33, no. 1-2, pp. 165-182, 1998.

[2] S. Sriputtirat, W. Boonkong, S. Pengprecha, A. Petsom, and N. Thongchul, "Low molecular weight poly(lactide-cocaprolactone) for tissue adhesion and tetracycline hydrochloride controlled release in wound management," Advances in Chemical Engineering and Science, vol. 2, no. 1, pp. 15-27, 2012.

[3] L. Ghasemi-Mobarakeh, M. P. Prabhakaran, M. Morshed, M. Nasr-Esfahani, and S. Ramakrishna, "Electrospun poly( $\varepsilon$-caprolactone)/gelatin nanofibrous scaffolds for nerve tissue engineering," Biomaterials, vol. 29, no. 34, pp. 4532-4539, 2008.

[4] P. X. Ma, "Biomimetic materials for tissue engineering," Advanced Drug Delivery Reviews, vol. 60, no. 2, pp. 184-198, 2008.

[5] C. Y. Xu, R. Inai, M. Kotaki, and S. Ramakrishna, "Aligned biodegradable nanofibrous structure: a potential scaffold for blood vessel engineering," Biomaterials, vol. 25, no. 5, pp. 877886, 2004.

[6] L. H. Chong, M. M. Lim, and N. Sultana, "Polycaprolactone(PCL)/gelatin $(\mathrm{Ge})$-based electrospun nanofibers for tissue engineering and drug delivery application," Applied Mechanics and Materials, vol. 554, pp. 57-61, 2014.

[7] N. Ashammakhi, A. Ndreu, Y. Yang, H. Ylikauppila, and L. Nikkola, "Nanofiber-based scaffolds for tissue engineering,"
European Journal of Plastic Surgery, vol. 35, no. 2, pp. 135-149, 2012.

[8] M. C. Beilke, J. W. Zewe, J. E. Clark, and S. V. Olesik, "Aligned electrospun nanofibers for ultra-thin layer chromatography," Analytica Chimica Acta, vol. 761, pp. 201-208, 2013.

[9] J. Miao, M. Miyauchi, T. J. Simmons, J. S. Dordick, and R. J. Linhardt, "Electrospinning of nanomaterials and applications in electronic components and devices," Journal of Nanoscience and Nanotechnology, vol. 10, no. 9, pp. 5507-5519, 2010.

[10] K. L. Ou, C. S. Chen, L. H. Lin et al., "Membranes of epitaxiallike packed, super aligned electrospun micron hollow poly(llactic acid) (PLLA) fibers," European Polymer Journal, vol. 47, no. 5, pp. 882-892, 2011.

[11] F. Roozbahani, N. Sultana, A. F. Ismail, and H. Nouparvar, "Effects of chitosan alkali pretreatment on the preparation of electrospun PCL/chitosan blend nanofibrous scaffolds for tissue engineering application," Journal of Nanomaterials, vol. 2013, Article ID 641502, 6 pages, 2013.

[12] J. Doshi and D. H. Reneker, "Electrospinning process and applications of electrospun fibers," Journal of Electrostatics, vol. 35, no. 2-3, pp. 151-160, 1995.

[13] E. J. Chong, T. T. Phan, I. J. Lim et al., "Evaluation of electrospun PCL/gelatin nanofibrous scaffold for wound healing and layered dermal reconstitution," Acta Biomaterialia, vol. 3, no. 3, pp. 321330, 2007.

[14] N. Bhardwaj and S. C. Kundu, "Electrospinning: a fascinating fiber fabrication technique," Biotechnology Advances, vol. 28, no. 3, pp. 325-347, 2010.

[15] T. J. Sill and H. A. von Recum, "Electrospinning: applications in drug delivery and tissue engineering," Biomaterials, vol. 29, no. 13, pp. 1989-2006, 2008.

[16] X. Liu, T. Lin, J. Fang et al., "In vivo wound healing and antibacterial performances of electrospun nanofibre membranes," Journal of Biomedical Materials Research-Part A, vol. 94, no. 2, pp. 499-508, 2010.

[17] W.-J. Li, C. T. Laurencin, E. J. Caterson, R. S. Tuan, and F. K. Ko, "Electrospun nanofibrous structure: a novel scaffold for tissue engineering," Journal of Biomedical Materials Research, vol. 60, no. 4, pp. 613-621, 2002.

[18] I. Armentano, M. Dottori, E. Fortunati, S. Mattioli, and J. M. Kenny, "Biodegradable polymer matrix nanocomposites for tissue engineering: a review," Polymer Degradation and Stability, vol. 95, no. 11, pp. 2126-2146, 2010. 
[19] T. D. J. Heunis and L. M. T. Dicks, "Nanofibers offer alternative ways to the treatment of skin infections," Journal of Biomedicine and Biotechnology, vol. 2010, Article ID 510682, 10 pages, 2010.

[20] S. Sriputtirat, W. Boonkong, S. Pengprecha, A. Petsom, and N. Thongchul, "Low molecular weight poly(lactide-cocaprolactone) for tissue adhesion and tetracycline hydrochloride controlled release in wound management," Advances in Chemical Engineering and Science, vol. 2, pp. 15-27, 2012.

[21] E.-R. Kenawy, G. L. Bowlin, K. Mansfield et al., "Release of tetracycline hydrochloride from electrospun poly(ethyleneco-vinylacetate), poly(lactic acid), and a blend," Journal of Controlled Release, vol. 81, no. 1-2, pp. 57-64, 2002. 

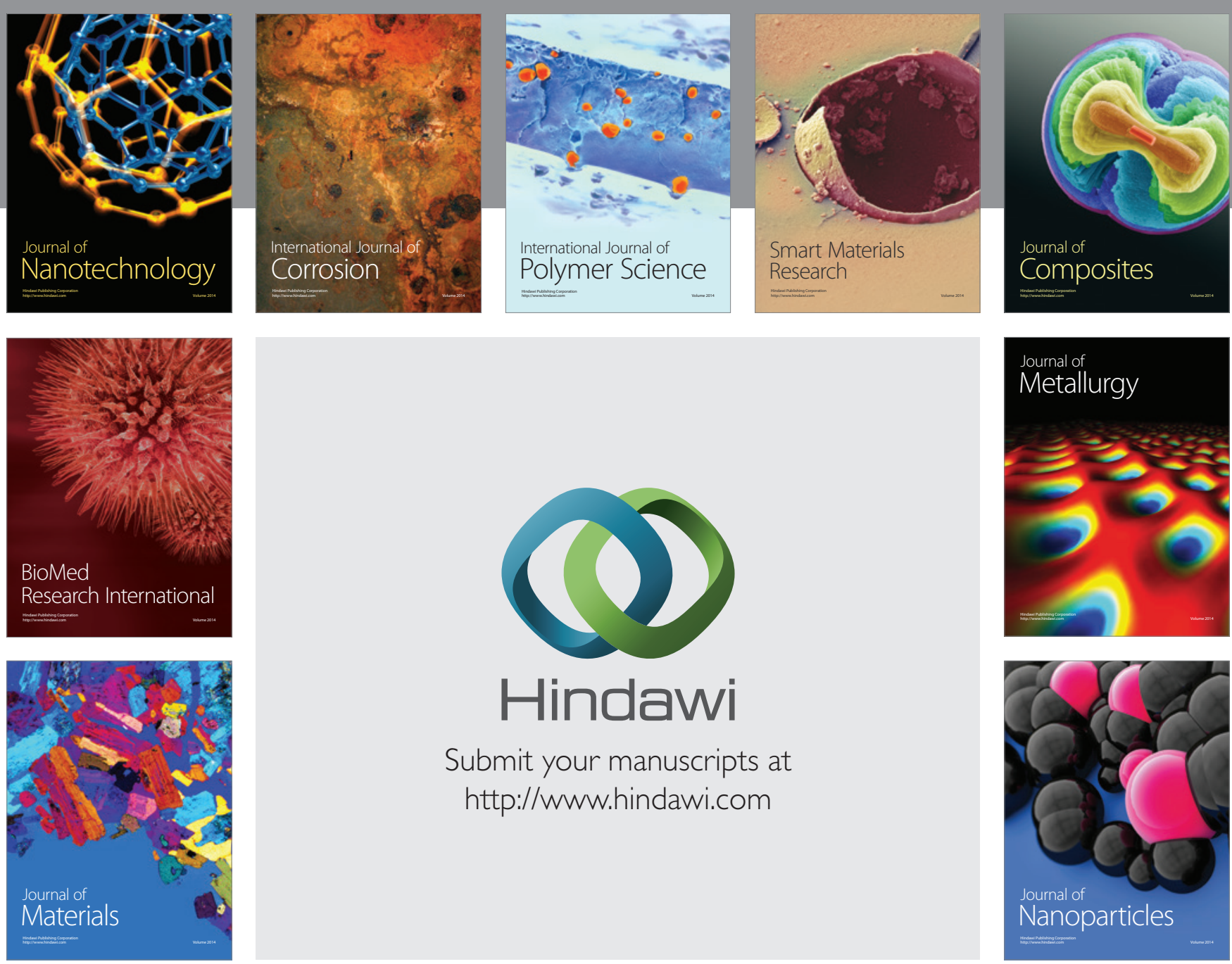

Submit your manuscripts at http://www.hindawi.com
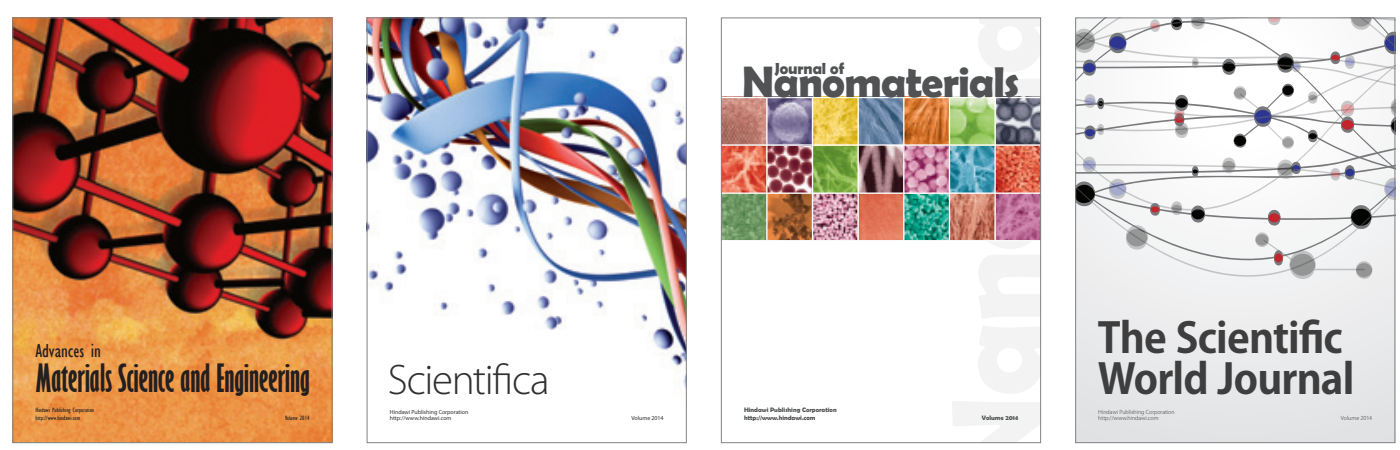

\section{The Scientific World Journal}
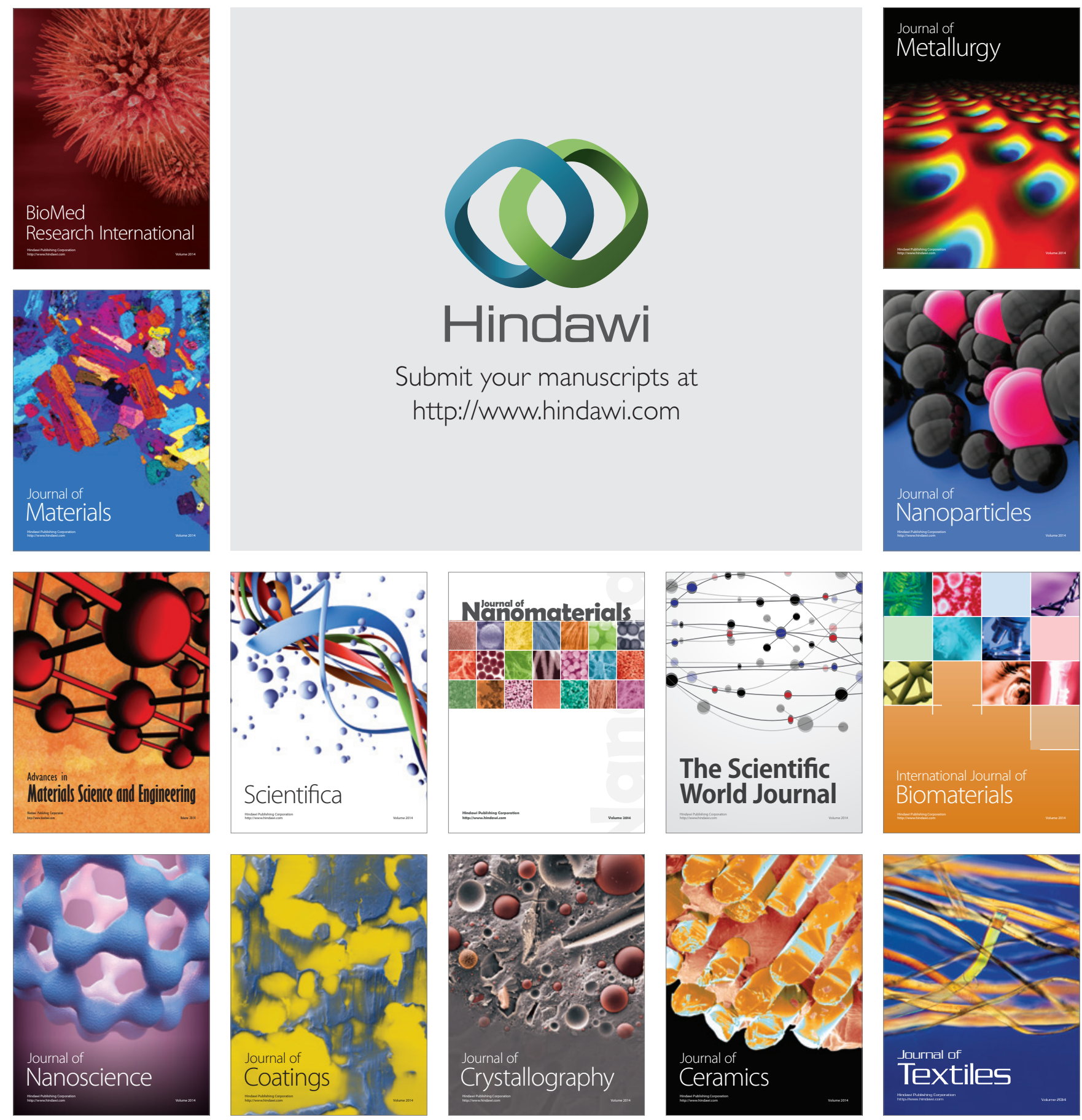